\title{
a hegemonia europeia e a falta da arte oriental no departamento de artes visuais da UnB 1
}

Mariana Alves Lopes

1

Este artigo apresenta, de forma modificada, o projeto de pesquisa elaborado como requisito para a aprovação na disciplina Projeto Interdisciplinar ministrada pelo prof. Dr. Cayo Honorato no Curso de Graduação em Artes Visuais (Bacharelado/Licenciatura) pelo Departamento de Artes Visuais da Universidade de Brasília no primeiro semestre de 2017. 
Introdução

Essa pesquisa será realizada para a busca de respostas sobre o porquê de, no Departamento de Artes Visuais (VIS) da UnB, ser enfatizado o conhecimento artístico de uma parte tão pequena de um planeta tão vasto: sobre o porquê de mal vermos história da arte oriental no departamento, ao longo da formação. Nesse sentido, a pesquisa não será sobre a arte em si, mas principalmente sobre a colonização do saber, o sistema capitalista no qual estamos inseridos, o poder econômico concentrado em alguns territórios do mundo, concedendo certa autoridade, que diz respeito principalmente à questão da dominação dos mais ricos sobre outros, definindo quais produções no mundo têm mais valor, seja ele estético, cultural, espiritual ou financeiro.

Algumas formas de expressão, como as construções e esculturas de impérios antigos que não são de origem europeia, não possuem a mesma atenção daquelas que o são. Às vezes até são comentados alguns pontos sobre as primeiras, no entanto, só quando estão de alguma forma relacionados à história da arte europeia. Na maioria das vezes, tais formas de expressão só são expostas quando essas culturas se chocam ou se cruzam em algum ponto da história com o continente Europeu, sendo mencionadas de maneira mais superficial. Muitas vezes as preferências por outros ramos da arte que não são os óbvios, condicionados e considerados intelectuais, nos deixa um pouco restrito quanto ao acesso a diferentes conhecimentos. Existe um padrão determinado daquilo que deve ser considerado arte de grande valor, assim como daquilo que não tem tanto valor assim, bem como o que pode ser considerado arte e artesanato ou arte erudita e a arte popular. Buscar respostas para essas questões é parte da pesquisa. Não entendendo os motivos de ver tantos detalhes de igrejas europeias ao se cursar história da arte, questionei o porquê não poderia ser visto também algo sobre a arquitetura chinesa, por exemplo, ou sobre as mesquitas islâmicas, que possuem milhares de detalhes e riquezas com a mesma profundidade que as primeiras. 
Bem como construções egípcias, mesopotâmicas, pintura chinesa, templos japoneses e esculturas persas. O domínio dos Estados Unidos e da Europa sobre esses povos, com a desculpa de orientá-los ainda causa todas essas divergências, de vermos mais história da arte do Ocidente e menos do Oriente como se a do Oriente fosse menos importante. A pesquisa será em resumo sobre o porquê de vermos tão pouca história do arte oriental no Departamento de Artes Visuais da UnB, descolonizando a Arte.

\section{Objeto Bruto}

Oriente e Ocidente são conceitos que foram definidos no Império Romano para organizar os territórios e os seus poderes. Oriente é um dos pontos cardeais, significando onde nasce o Sol, correspondendo portanto ao Leste. Este termo, que na época passou a definir os territórios que estavam ao leste da Europa, como a Ásia e parte da África, foi um termo criado pelos ocidentais, para denominar países que eram diferentes deles e que em algum momento estariam sob o seu domínio. Estudei detalhes e arquiteturas de igrejas cristãs e tudo o que se refere à igreja católica e seus santos. Mas em nenhum momento presenciei aulas que mostrassem os Deuses do Oriente, templos budistas, hindus, Egito, ou a Arte Islâmica, por exemplo.

Na História da Arte Antiga, tem Grécia, Império Romano, Arte Bizantina, Românica e umas poucas referências aos Persas, que a princípio eram os denominados povos bárbaros, sempre mencionados como povos menos inteligentes e perigosos devido às suas ameaças aos povos que seriam hoje chamados de ocidentais; mas vi pouco dos detalhes da arquitetura, escultura e pintura dos Bárbaros. Deve-se ressaltar neste contexto a busca pelo poder e domínio existente em toda a história da humanidade desde tempos como por exemplo do Império Macedônico, com Alexandre que domina a Pérsia, até o grande Império Romano. 
Bem como Napoleão, e tudo o que ocorreu na história dentro do caráter colonizador dos povos do mundo, e como o nosso olhar pode ser condicionado por aqueles que estão no domínio. O conceito de Oriente então, parece restringir e reduzir estes países. Será o Oriente um lugar com menos valor do que o Ocidente? Com menos riqueza cultural e artística? Talvez exista um fator dominador na resposta, como Edward W. Said (1978) menciona em seu livro Orientalismo, no qual ele mostra que, na verdade, o Oriente é uma invenção do Ocidente. Isso quer dizer que é o Ocidente que fala pelos orientais, interfere nas suas decisões, determinando ou definindo o que é Oriente. O próprio Oriente não fala por si. O que se conhece por Oriente é, na verdade, a visão que o Ocidente tem destes territórios e de seus povos.

Segundo Said, na visão dos ocidentais (partindo primeiramente dos europeus), os orientais são os exóticos, excêntricos, não são capazes de se definirem por si mesmos, são muito diferentes dos europeus em costumes, regras e crenças. Mas essa diferença também pode ser definida de maneira geográfica. Em termos territoriais, o Oriente diz respeito à partes da África e da Ásia, onde o próprio Ocidente os definiu.

Existe tanta riqueza na arquitetura japonesa, nos templos budistas e islâmicos quanto nas igrejas católicas antigas e, apesar das disciplinas de história da arte ofertadas no VIS não mencionarem explicitamente que a arte oriental é inferior, não é possível se aprofundar nela. Ainda existe muita dominação da Igreja Católica desde os tempos da Inquisição. Ela ainda domina boa parte da história disponível em livros. Além da própria Universidade, buscar detalhes sobre a arte no Oriente em outros lugares é muito difícil. É desproporcional a diferença entre as fontes de informação sobre elas, mas ainda assim é possível encontrá-las, como no livro Uma Nova História da Arte de Julian Bell, em que ele apresenta a Arte abrangendo um espaço muito maior, trazendo partes da Ásia, da Oceania, África, Irã, Índia, China, Japão, Indonésia e outros países, muitas vezes esquecidos. 
Em toda a história é possível encontrar a força com que a Europa deseja impor a sua maneira a todos os demais povos. O eurocentrismo existe e ainda sofremos os resultados da colonização, que se deu de forma diferente na América Latina e na Ásia pelos anglosaxões. Na Índia, por exemplo não houve a exterminação de tudo o que havia em termos de cultura, filosofia e outros princípios sociais. Ainda é possível ver, com certa clareza, detalhes do passado pré-colonial indiano, das sociedades que lá habitavam antes da colonização. Existe uma Índia Antiga que ainda é viva nos dias atuais. Já na América Latina os portugueses e os espanhóis destruíram muito do que existia. Os estudos póscoloniais e a teoria decolonial questionam a hegemonia europeia, e isso não se dá só no campo das Artes. Isso também faz referência ao patriarcado, colocando em pauta questões de gênero, bem como questões raciais, econômicas e de classe social.

Entrando em acordo com o conceito de Orientalismo dado pela leitura de Edward Said e estudando este conceito na atualidade, penso em uma forma de sair da dicotomia Oriente e Ocidente, Arte e Artesanato, Opressor e Oprimido, e buscar uma Arte que seja mais Universal. Como por exemplo as artes nativas e regionais da América Latina serem classificada em sua maioria como artesanato, enquanto a arte europeia tem valor de arte erudita, ou uma arte de verdade, com maior potencial intelectual e econômico. Ainda que a História da Arte seja por si só um conceito Ocidental, não se pode de forma alguma, afirmar que só existe essa história da arte. Existe um ponto em que as barreiras devem ser quebradas e que os valores devem ser revistos.

\section{Problematização}

O conceito de uma arte não-ocidental é parte fundamental do meu projeto. O Ocidental, então, seria definido por tudo aquilo que já foi chamado de Arte na historiografia da História da Arte, dentro de uma visão eurocêntrica, que limita a arte europeia como a verdadeira arte. Talvez o foco do meu projeto, a princípio, esteja no Oriente. 
Sendo aqui, Oriente tudo aquilo que diz respeito à Índia, China, Japão, Tailândia, Irã, Marrocos, Indonésia, Turquia, Egito, entre outros países de caráter exótico e excêntrico (tal como foram definidos pelos ocidentais), baseando-se nos países que estão dentro deste conceito, localizados nos continentes asiático e africano.

Como trazer então a arte desses países para o VIS de maneira mais aprofundada? É necessário um processo de descolonização da história da arte no Departamento de Artes da UnB, se libertando da autoridade europeia. Começo, então, por esses países orientais, devido à antiguidade de suas filosofias, religiões, crenças, construções e sociedades, que se mantém vivas até hoje. De início, perceber o vasto conteúdo abordado sobre igrejas católicas e nenhum sobre templos hindus ou mesquitas islâmicas, por exemplo, foi o que me causou maior dúvida, me fazendo perceber a necessidade de buscar uma História da Arte além da óbvia. Talvez este projeto se relacione a uma produção mística ou sagrada, relacionado a templos, lugares sagrados, objetos e esculturas que expressem caráter devocional ou esotérico, em sua maior parte dizendo respeito à antiguidade e ao período pré-colonial. Como desconstruir a hegemonia da igreja católica sobre templos e construções ligadas a outras religiões dentro da história da arte transmitida no VIS?

O projeto menciona de maneira bem menos profunda a arte nativa e a arte latinoamericana, bem como a arte africana e afro-brasileira, já que são matérias com as quais muitas vezes podemos entrar em contato no Departamento de Artes Visuais, sendo elas mais acessíveis e exploradas, já que existem professores pesquisadores destas áreas na UnB. Farei referência também à artificação de determinados objetos desses povos de cultura não-ocidental tradicional, como os orientais, nativos, latinoamericanos, africanos e outros que não dizem respeito à Europa se fazendo assim uma apropriação de ferramentas, objetos ou vestimentas, bem como à exposição destes utensílios em museus com o status de Arte, já que na maioria das vezes não chegam a ter essa classificação para os estudiosos da arte, entrando no conceito de Artesanato. 
Nesse sentido, Artesanato é um conceito e uma classificação dada por aqueles que não a produziram, como maneira de desqualificar os conteúdos daqueles objetos e ações. Existe um grande problema nessa imposição de valores por outros, que não aqueles que executam ou produzem as obras, reduzindo assim esses povos e essas culturas, como se eles mesmas não tivessem o poder de definirem a si mesmos. Por que isso acontece? Dentro do termo Orientalismo, Said desenvolve que são os ocidentais que tomam para si o direito de definirem, oprimirem e controlarem assuntos de outros territórios que eles classificam como Orientais. Isso não ocorre apenas com o Oriente, mas com tudo aquilo que não é o Ocidente.

De onde vem as classificações das Artes? Por que elas se mantém e por que devemos aceitar essas imposições? Está além dos livros sobre Arte, entender as histórias das civilizações talvez seja mais coerente, como acontece no livro de Fernand Braudel $A s$ estruturas do Cotidiano: Civilização Material, Economia e Capitalismo, séculos XV ao XVIII. Entender estes problemas é compreender o porquê isso também acontece dentro do VIS, sendo este um projeto de pesquisa focado no currículo das artes.

Justificativa

Existe mais na história da arte do que apenas Europa. Bem como também existem mais formas de espiritualidade ou religião além do Cristianismo e da Igreja Católica. Mas, como se toda a História da Arte se encerrasse nisso, vemos pouco ou quase nada sobre o Oriente. E muito sobre o Ocidente, mesmo o Oriente sendo tão rico em termos culturais, religiosos e artísticos. A pesquisa será feita com a justificativa de trazer questões sobre a possibilidade de ampliar os campos de estudo dentro do ensino da Arte na UnB, fazendo um convite a um ensino mais abrangente, que englobe mais partes e culturas do mundo. Busco a partir de uma visão pós-colonial utilizar os conceitos e as pesquisas sobre a descolonização da História da Arte. 
Essa pesquisa se faz necessária, já que é de grande importância abrir o campo de estudos e pesquisa das Artes para outros campos além do Ocidente Europeu. A falta de um ensino baseado na cultura Oriental dentro da universidade está ligada em grande parte à história da colonização dos territórios do mundo e quem os governa. Buscando as diferenças entre as fontes de pesquisa do Oriente e do Ocidente, usando como referência o livro Orientalismo, de Edward Said, e seus estudos sobre a questão Oriental, é necessário lembrar que mesmo após o período colonial a Europa ainda interfere muito nos países orientais. No que se refere às estruturas políticas e culturais do planeta e a como a busca incessante pelo poder afetou o mundo e o seu funcionamento nos dias de hoje, utilizarei também em minha pesquisa o livro de Fernand Braudel, As estruturas do Cotidiano: Civilização Material, Economia e Capitalismo, séculos XV ao XVIII.

Existem livros sobre a História da Arte, que já trazem uma visão mais expandida e realista da Arte, já que não despreza outros países e culturas, como o livro Uma Nova História da Arte, de Julian Bell. Trazendo com ele uma possibilidade de se aprofundar também na Arte destes outros, que não sejam os Ocidentais. E é exatamente o que a minha pesquisa deseja expor: a necessidade de mostrar que existem várias culturas para se aprofundar em estudos da arte oriental.

Dentro dessa pesquisa, será exposto como o domínio de países com maior poder econômico se sobrepõe a outros. Sendo assim alguns países e até continentes ficam à deriva dentro da história da Arte, e já que não são aprofundados na Universidade em que estudo, pode-se deduzir que estes territórios possuem menor importância acadêmica. Este projeto então pretende organizar uma pesquisa em que se encontre meios para verificar essa dedução. Chegando a uma conclusão sobre as outras classificações da Arte, como Artesanato e Arte Erudita, por exemplo. Todos estes conceitos reforçam uma visão europeia dizendo respeito a valores. É por isso também que é dada a importância dessa pesquisa. 
Existe a necessidade de estarmos atentas ao conhecimento do que é arte para estes outros territórios e povos, além do conceito que é dado no Ocidente e pelo o Ocidente, que na maioria das vezes classifica e determina produções que não dizem respeito a eles próprios. Aproveitando o fato de que, em geral, existe um laço forte e predominante entre religiosidade e cultura, os espaços do meu interesse seriam o Irã e a Índia. A ligação entre a Arte e Deus é um fator comum em todo o mundo antigo, inclusive no Ocidente, sendo assim, o caráter religioso é, e ao mesmo tempo não é, o que define a importância de cada espaço. A religião define algumas produções artísticas apresentadas em aulas de História da Arte, apenas quando se fala do catolicismo, que sendo de caráter Ocidental, também é de caráter dominador.

Em uma mistura de arte, história, dominação e poder, se faz a procura de um conhecimento mais amplo e agregador. Algo que talvez já esteja se fazendo presente, como pude perceber ao ler o edital da prova específica de Artes Visuais da UnB, em que os livros Arte indígena no Brasil da Els Lagrou e Arte Afro-Brasileira do Roberto Cunduru se encontram na bibliografia. Agora estudando e buscando também fontes que dizem respeito à Arte do Oriente e suas obras, vem o desejo de ter essa ampliação.

\section{Objetivos}

1. Mostrar a necessidade de haver uma História da Arte Visual mais abrangente

2. Esclarecer os motivos da História da Arte europeia ser dominante na UnB

3. Mostrar que existe Arte do Oriente além da disponível nas aulas do Departamento

4. Fazer uma pesquisa sobre o colonialismo e a questão da hegemonia europeia.

5. Mostrar conteúdos sobre Mesquitas e outros templos religiosos ou espiritualistas que não digam respeito à Igrejas Católicas.

6. Ampliar o conhecimento sobre as Histórias da Arte.

7. Associar Arte/Deus como fatores comuns no Ocidente e no Oriente 


\section{Metodologia}

A pesquisa será feita a partir da leitura da bibliografia dos livros já expostos e também da leitura de dissertações e teses que digam respeito principalmente à arte oriental, à historiografia da arte, à teoria decolonial e a como a construção do mundo influenciou nas classificações dos valores das produções artísticas dos países no período atual. Como os fatos na história da formação das civilizações serão a base para a pesquisa, ela também será de caráter histórico.

Será primordial selecionar capítulos específicos dos livros utilizados quem tenham maior fonte de conhecimentos e respostas. Fazendo um resumo de cada um deles e organizando em tópicos aquilo que for de maior valor para a pesquisa. Buscarei entrevistar ou conversar com alguns professores do Departamento para obter diferentes opiniões sobre minha pergunta de pesquisa.

Levantarei dados quantitativos: quantos livros que mencionam a História da Arte Oriental estão na bibliografia das matérias oferecidas pelo instituto de Artes Visuais? Farei também uma pesquisa de quantos professores dentro do Departamento oferecem matérias associadas a este tipo de conhecimento? Ao que se limita a história da Arte no VIS? Será uma pesquisa também baseada na opinião de outros professores e estudiosos da Arte, tendo caráter descritivo.

\section{Referências Bibliográficas}

BELL, Julian . Uma Nova História da Arte. São Paulo: Martins Fontes, 2008.

BONNICI, T. O pós-colonialismo e a literatura: estratégias de leitura (1900 a 2001). [online]

BRAUDEL, F. Civilização Material, Economia e Capitalismo séculos XV ao XVIII: As Estruturas do cotidiano. São Paulo: Martins Fontes, 2005

SAID, Edward. Orientalismo. O Oriente como invenção do Ocidente. São Paulo: Cia das Letras, 1996. 